\title{
Post-Landing Orion Crew Survival in Warm Ocean Areas: A Case Study in Iterative Environmental Design
}

\author{
George E. Rains ${ }^{1}$, Grant C. Bue ${ }^{2}$, Jerry Pantermuehl ${ }^{1}$ \\ ${ }^{1}$ ESCG-Jacobs-Svedrup, Houston TX \\ ${ }^{2}$ NASA Johnson Space Center, Houston TX
}

Copyright $@$ SAE International

\begin{abstract}
The Orion crew module (CM) is being designed to perform survivable land and water landings. There are many issues associated with post-landing crew survival. In general, the most challenging of the realistic Orion landing scenarios from an environmental control standpoint is the offnominal water landing. Available power and other consumables will be very limited after landing, and it may not be possible to provide full environmental control within the crew cabin for very long after splashdown. Given the bulk and thermal insulation characteristics of the crew-worn pressure suits, landing in a warm tropical ocean area would pose a risk to crew survival from elevated core body temperatures, if for some reason the crewmembers were not able to remove their suits and/or exit the vehicle. This paper summarizes the analyses performed and conclusions reached regarding post-landing crew survival following a water landing, from the standpoint of the crew's core body temperatures.
\end{abstract}

\section{INTRODUCTION}

Following long-established standard practice in the aircraft industry, safety provisions for manned spacecraft have always included some arrangements for survival of the crew in contingency situations. These provisions have

varied across different vehicles, programs, and nations, but a common component has always been some capability for crew survival following an unplanned or off-nominal water landing.

Given the geography of the U.S. manned space program, where all manned launches have taken place eastward over the Atlantic Ocean, it was inevitable that all of NASA's early manned spacecraft would be capable of performing water landings. Since a water landing capability had to be provided, in any case, for the first astronauts to survive possible contingencies following a launch failure, it was expeditious for NASA to make water landing the normal mode of operation following a successful mission. This programmatic logic held true for Mercury, Gemini, and Apollo, and was revised only with the advent of the Space Shuttle. The new Orion spacecraft may return to water landing as the normal mode of operation, but with additional capability for post-landing crew support.

\section{Previous NASA Experience}

\section{Mercury [1]}

Due to the constraints imposed by technology, vehicle weight, and very aggressive program schedules, the capability of Mercury capsules to sustain their sole occupants following landing was very limited. The capsules were always intended to land in the ocean; investigations into the possible consequences of an unplanned landing on dry land were also apparently very limited. Nevertheless, the capsules did not float very well, and there were no on-board provisions for additional vehicle flotation beyond the limited inherent buoyancy of the capsule. One Mercury capsule, that of Virgil "Gus" Grissom, was lost when it quickly filled with water following a 
premature hatch opening. Another, containing a chimpanzee test subject named "Ham," was almost lost when it sustained damage on landing that allowed the water to leak in more slowly.

Mercury astronauts were provided with a small inflatable dinghy as part of their personal emergency equipment, but the only astronaut who needed to make use of it following his flight was Scott Carpenter. He came down some 250 miles past his intended landing zone, and had to exit his capsule and then wait 3 hours in the water before being picked up. The other Mercury astronauts were all recovered less than an hour after landing. Alan Shepard and Gus Grissom both exited their capsules and were in the water briefly before being hoisted aboard a helicopter. "Ham," John Glenn, Walter Schirra, and Gordon Cooper all remained inside their capsules until after the capsule was brought aboard the recovery ship.

\section{Gemini [2]}

The two-man Gemini capsule was a significantly enlarged and refined version of the original Mercury design. Gemini missions were still intended to conclude with a landing in the ocean, and again the capability of capsules to sustain their occupants following splashdown was very limited.

In seven of the ten manned Gemini flights, at the end of the mission the crewmembers exited the vehicle while it was still in the water, and were then individually hoisted aboard a recovery helicopter. Two crews (those of Gemini 6 and 9) elected to remain within the capsule until after it was lifted onto the recovery ship. In all nine of these missions, the spacecraft came down very close to its intended landing point, and divers were present to quickly attach an additional flotation collar to the outside of the spacecraft. The flotation collar represented a significant improvement compared to Mercury, and lessened the danger that the spacecraft would fill with water and sink, either due to damage or when the hatches were opened.

Only one mission, Gemini 8, had what could be considered a contingency or off-nominal landing. Following the on-orbit failure of a maneuvering thruster, the crew (Neil Armstrong and David Scott) had to conduct an emergency de-orbit to a pre-designated secondary landing site. The vehicle landed outside of helicopter range from the nearest aircraft carrier, and the sea was quite rough, with sea swells of 4 to 5 meters in height. However, larger land-based search and rescue aircraft were in the air and on the way to the projected landing site as soon as the emergency was declared. Three rescue divers jumping from the first aircraft to arrive were able to attach a flotation collar to the outside of the spacecraft 45 minutes after splashdown.

Despite some nausea caused by the high seas, the crew were still able to climb a rescue ladder onto the first ship to arrive, a U.S. Navy destroyer, approximately 3 hours after splashdown. This feat may have been possible only because of the short duration of the flight, as the thruster failure occurred early in the mission, and Gemini 8 was in space for less than 11 hours.

\section{Apollo}

Following on the obvious utility of the Gemini flotation collar, the three-man Apollo spacecraft retained this feature, and also added some seemingly minor, but significant, provisions for crew support after landing. Should the spacecraft roll over after it was in the water, inflatable balloons called "uprighting bags," installed near the top of the conical capsule beneath the parachutes, provided enough buoyancy to prevent the vehicle from remaining upside down. A battery-powered fan and ventilation openings were also added near the top of the vehicle, to provide fresh air and some cooling to the interior of the spacecraft after landing (with appropriate safety devices to prevent water ingestion or opening to vacuum while in space). However, support divers or para-jumpers were still needed in order to attach the separate flotation collar to the outside of the vehicle before the side hatch could be safely opened, as the base of the side hatch was only about 1.6 feet above the water level in a perfectly calm sea.

It was originally intended that the Apollo capsules would be able to land on dry land as well as water, but early drop testing revealed that the descent rates and impact loads were too high for safe landings on land. Correcting the problem would have delayed the program significantly, and would also have added 
considerably more mass to the spacecraft. Given the urgent and heated nature of the "space race" at the time, NASA decided that a land landing capability for Apollo was an unnecessary luxury, and all the Apollo capsules returning from space conducted water landings only.

Including the follow-on Skylab and Apollo-Soyuz flights, there were a total of fifteen manned missions of the Apollo spacecraft. All fifteen came down inside their planned landing zones, within easy helicopter range of a waiting aircraft carrier. At the conclusion of each of the eleven Apollo missions, divers first attached the external flotation collar, and then the three crewmembers opened the side hatch, exited the vehicle while it was still in the water, and were lifted aboard a recovery helicopter. The Apollo 8 mission recorded the longest time from splashdown to crew recovery (88 minutes), and the Apollo 9 mission encountered the roughest sea conditions, experiencing wind waves seven feet (2 meters) in height. Despite the high sea, the Apollo 9 crew was still recovered in a nearaverage time of 49 minutes after splashdown.

For the three long-duration Skylab missions and the single Apollo-Soyuz flight, the crewmembers remained within the capsule after splashdown, and did not exit the vehicle until after it was hoisted aboard the aircraft carrier.

\section{Space Shuttle}

Representing a clean break from previous NASA spacecraft, the reusable space shuttle was intended to make space travel easier, cheaper, more routine, and more like the operations of large aircraft. This entailed the adoption of aircraft-style runway landings, and greater risk to the crew in the event of an off-nominal landing.

For the first four shuttle flights, the two crewmen were provided with aircraft-style ejection seats, parachutes, and individual survival gear.

Following STS-4, the ejection seats were removed, and the crew size was increased, to as many as eight people on some flights. From the STS-5 mission through STS-51L (the 25th shuttle flight), the crews had no parachutes, and there were no provisions for exiting the vehicle until after landing. While it was never intended or imagined that a space shuttle could float after a water landing, a single large life raft and survival equipment were nevertheless provided, in the hope that the crew would be able to egress the vehicle before it sank.

Following the loss of the space shuttle Challenger on STS-51L, more thorough studies were conducted of shuttle abort modes and contingency water landings. It was determined that, even when in controlled gliding flight, the shuttle's high landing velocity compared to normal aircraft would most likely lead to a catastrophic breakup of the vehicle upon contact with the water. The only way for the crew to survive an impending water landing would be to bail out first.

This realization led to the addition of an in-flight bailout system, carried on every subsequent shuttle flight, featuring pressure suits, individual parachutes, small enclosed personal life rafts, and communications and survival gear. A telescoping guide pole was also necessary so that crewmembers bailing out of the side hatch would not hit the wing.

Once in the water, the greatest threat to surviving crewmembers was thought to be hypothermia (cold). An internal shuttle program study estimated crew survival time as more than 12 hours immersed in $40^{\circ} \mathrm{F}$ water (suit only), and more than 22 hours in the personal life raft in $40^{\circ} \mathrm{F}$ water and $40^{\circ} \mathrm{F}$ rain (suit plus raft).

\section{Orion Design Requirements}

The original concept for the Orion spacecraft was of a simple, flexible, economical vehicle that would be re-usable, and which could land safely on either dry land or water, under a wide variety of environmental conditions. It was initially presumed that the normal return mode would be to dry land, at one of several suitable sites in the western U.S. This was primarily due to the simplicity and lower cost of recovery operations and vehicle refurbishment, compared to a water landing.

Among the various design requirements intended to implement the above concept, the following addressed post-landing crew survival for water landings: 
Orion shall provide for crew survival, without permanent crew disability, for at least 36 hours with the hatch closed in sea state conditions defined in CxP 70023,

Constellation Program Design Specification for Natural Environments (DSNE), sections 3.5.18 through 3.5.20 and 3.6.18 through 3.6.20.

The relevant call-outs from the Design Specification for Natural Environments document were originally documented as follows:

- DSNE 3.5.18, Sea State for Water Landing (Design Limits)

- Maximum significant wave height (SWH): 30 feet $(9 \mathrm{~m})$

- Maximum wind speed: 40 knots $(20.6 \mathrm{~m} / \mathrm{s})$

- Minimum wave period associated with maximum SWH: 12 seconds

- DSNE 3.5.19, Sea State for Crew Rescue (Design Limits)

- Maximum significant wave height (SWH): 13 feet $(4 \mathrm{~m})$ (TBR)

- Maximum wind speed: 27 knots $(13.9 \mathrm{~m} / \mathrm{s})($ TBR $)$

- Minimum wave period associated with maximum SWH: 8 seconds (TBR)

- DSNE 3.5.20, Sea Surface Temperature for Water Landings (Design Limits)

- Maximum $36^{\circ} \mathrm{C}\left(97^{\circ} \mathrm{F}\right)$

- Minimum $-2^{\circ} \mathrm{C}\left(28^{\circ} \mathrm{F}\right)$

- Note that sea surface temperature and wave height parameters are independent such that maximum wave height can be concurrent with minimum sea surface temperatures.

\section{Water Landing Environments}

As the design of the Orion spacecraft progressed, questions were raised regarding the survival prospects of an Orion crew that might find themselves at sea for 36 hours under one or more of the conditions listed above. A design study was undertaken in early 2007 that examined both the possible water landing environments, and the physiological responses of Orion crewmembers under a range of possible cabin conditions.

This study found that the actual occurrence of a sea surface temperature of $36^{\circ} \mathrm{C}\left(97^{\circ} \mathrm{F}\right)$ was quite rare on an annualized, global basis, basically occurring only within the restricted waters of the Persian Gulf and southern Red Sea in local summer. Sea surface temperatures in the open ocean were found to rarely, if ever, exceed $31^{\circ} \mathrm{C}\left(88^{\circ} \mathrm{F}\right)$.

The DSNE note regarding the independence of wave height and sea surface temperatures was also found to need further clarification. The example given in the original specification, that maximum wave height can be concurrent with minimum sea surface temperatures, is true. But the implication that maximum wave height could also be concurrent with maximum sea surface temperatures was found to be false. In fact, a fairly strong negative correlation was found to exist between wave height and sea surface temperature - in general, the higher the waves, the colder the sea surface, and the warmer the water, the lower the wave heights.

Based on these results, Section 3.5.20 of the DSNE was then officially revised as follows:

- DSNE 3.5.20, Sea Surface Temperature for Water Landings (Design Limits)

- Maximum $31^{\circ} \mathrm{C}\left(88^{\circ} \mathrm{F}\right)$

- Minimum $-2^{\circ} \mathrm{C}\left(28^{\circ} \mathrm{F}\right)$

- Note that sea surface temperature and wave height parameters are independent such that maximum wave height can be concurrent with minimum sea surface temperatures. Significant wave heights of more than 4 meters have not been observed to be concurrent with maximum sea surface temperature, except in the Northern Indian Ocean / Arabian Sea from Jun-Aug. 


\section{Human Thermal Modeling}

In order to assess the impact of the hot postlanding environments on the crew, both in suited and unsuited conditions, a parametric study was conducted using a thermal model of the human body, the Wissler Human Thermal Model (WHTM) software program [1]. The Wissler program has been subsequently adapted for the personal computer [2]. The Wissler program was developed by Eugene $\mathrm{H}$. Wissler of the University of Texas at Austin to simulate the physical characteristics of the human thermal system in a transient state. The model divides human body into 15 cylindrical elements and the user is allowed to specify various subject, garment, and environmental parameters. The major body elements are upper torso, lower torso, head, and 3 elements for each arm and leg. Within each of the body elements there are 15 radial points or nodes that represent bone, muscle, fat and skin and there are a number of time-dependent variables and user specified parameters, as follows:

\section{Time-dependent computed variables}

- Temperatures at 15 radial nodes within each body element

- Arterial and veinous blood temperatures at each radial node

- Local perfusion rate at each radial node

- Metabolic rate at each node owing to resting metabolism, exercise and shivering

- Oxygen, carbon dioxide, and lactate concentrations in tissue and blood at each radial node

- Regional rates of sweat production

- Rate of sweat evaporation, which may be less that the rate of sweat production

- Ventilation rate

- Temperatures at up to 6 additional radial nodes representing clothing

- Amount of accumulated sweat at each clothing node

- Rate of heat transfer between exposed surfaces and the environment owing to convection and radiation

\section{User Specified Parameters}

- Subject's weight and mean skin fold thickness or regional subcutaneous fat thicknesses

- Thermal resistance and permeability for water vapor of the clothing on each body element
- Resting and total metabolic rates (exclusive of shivering)

- Environmental conditions, including the drybulb temperature, humidity, pressure, wind speed for a gas or temperature and fluid speed for liquid.

- Internal air ventilation temperature, humidity, and flow rate.

- Liquid cooling garment inlet temperature and flow rate

The WHTM has been used successfully to model the human thermal response in a variety of suited and unsuited conditions [3,5-7], and compared favorably to 41-Node Metabolic Man program simulations $[8,9]$.

For these postlanding simulations a $154 \mathrm{lbm}$ crewperson was assumed. When suited, the previously correlated insulation properties of the Advanced Crew Escape Suit (ACES) with no liquid cooling or internal ventilation were assumed for the Orion analysis [5,6]. A metabolic rate profile was developed with the Medical Division, consisting of 500 BTU/hr for the first hour following splashdown, followed by $585 \mathrm{BTU} / \mathrm{hr}$ for a half hour corresponding to active emesis, and the remainder of the 36 hours at 452 BTU/hr, reflecting sea sickness without emesis [10].

Selected analysis results are presented in Table 1 and Table 2 for the unsuited and suited cases, respectively. The selected data were drawn from the $85 \%$ relative humidity cases, although simulations conducted at $90 \%$ and $95 \%$ relative humidity show substantial degradation in performance. Simulations were halted when core body temperatures rose above $38.89^{\circ} \mathrm{C}$ $\left(102{ }^{\circ} \mathrm{F}\right)$, the point where pyrexia tends to occur that is associated with severe sweating, fainting, dehydration and weakness. Unfortunately, as of now, the current standard for body core temperature as defined in CXP 70024, Constellation Program Human-Systems Integration Requirements (HSIR), is the lower value of $38.0^{\circ} \mathrm{C}\left(100.4^{\circ} \mathrm{F}\right)$. The suited performance is substantially less than the unsuited case, requiring air at a given flow rate and humidity, to be about $9^{\circ} \mathrm{C}\left(16.2^{\circ} \mathrm{F}\right)$ colder than the unsuited case for the same core temperatures. At air flow rates of $0.0244 \mathrm{~m} / \mathrm{s}$ (100 acfm), tolerable cabin air temperatures were $33.3^{\circ} \mathrm{C}\left(92^{\circ} \mathrm{F}\right)$ and $24.4^{\circ} \mathrm{C}\left(76^{\circ} \mathrm{F}\right)$, for the unsuited and suited configurations, respectively. At flow rates of $0.0049 \mathrm{~m} / \mathrm{s}$ (20 acfm), tolerable 
Table 1

Shirtsleeve 36-hour Postlanding Analysis Selected Results

\begin{tabular}{|cc|cc|cc|c|}
\hline \multicolumn{2}{|c|}{$\begin{array}{c}\text { Vehicle } \\
\text { Environment } \\
\text { Temperature }\end{array}$} & \multicolumn{2}{|c|}{ Air Flow Rate } & \multicolumn{2}{|c|}{$\begin{array}{c}\text { Core } \\
\text { Temperature }\end{array}$} & $\begin{array}{c}\text { Time to Reach } \\
\text { Core Temp } \\
\text { Limit }\end{array}$ \\
\hline Deg C & Deg F & m/s & $(\mathbf{a c f m})$ & Deg C & Deg F & Hours \\
\hline 21.1 & 70 & 0.0049 & $(20)$ & 36.72 & 98.1 & \\
\hline 21.1 & 70 & 0.0085 & $(35)$ & 36.67 & 98.0 & \\
\hline 21.1 & 70 & 0.0122 & $(50)$ & 36.67 & 98.0 & \\
\hline 21.1 & 70 & 0.0244 & $(100)$ & 36.61 & 97.9 & \\
\hline 27.8 & 82 & 0.0049 & $(20)$ & 37.06 & 98.7 & \\
\hline 27.8 & 82 & 0.0085 & $(35)$ & 37.00 & 98.6 & \\
\hline 27.8 & 82 & 0.0122 & $(50)$ & 37.00 & 98.6 & \\
\hline 27.8 & 82 & 0.0244 & $(100)$ & 37.00 & 98.6 & \\
\hline 32.2 & 90 & 0.0049 & $(20)$ & 38.50 & 101.3 & \\
\hline 32.2 & 90 & 0.0085 & $(35)$ & 38.06 & 100.5 & \\
\hline 32.2 & 90 & 0.0122 & $(50)$ & 37.78 & 100.0 & \\
\hline 32.2 & 90 & 0.0244 & $(100)$ & 37.39 & 99.3 & \\
\hline 33.3 & 92 & 0.0049 & $(20)$ & $>38.89$ & $>102.0$ & 5.96 \\
\hline 33.3 & 92 & 0.0085 & $(35)$ & $>38.89$ & $>102.0$ & 8.47 \\
\hline 33.3 & 92 & 0.0122 & $(50)$ & $>38.89$ & $>102.0$ & 15.32 \\
\hline 33.3 & 92 & 0.0244 & $(100)$ & 38.17 & 100.7 & \\
\hline 35.6 & 96 & 0.0049 & $(20)$ & $>38.89$ & $>102.0$ & 2.21 \\
\hline 35.6 & 96 & 0.0085 & $(35)$ & $>38.89$ & $>102.0$ & 2.39 \\
\hline 35.6 & 96 & 0.0122 & $(50)$ & $>38.89$ & $>102.0$ & 2.57 \\
\hline 35.6 & 96 & 0.0244 & $(100)$ & $>38.89$ & $>102.0$ & 3.15 \\
\hline
\end{tabular}

Table 2

Suited 36-hour Postlanding Parametric Analysis Selected Results

\begin{tabular}{|c|c|c|c|c|c|}
\hline \multicolumn{2}{|c|}{$\begin{array}{c}\text { Vehicle } \\
\text { Environment } \\
\text { Temperature }\end{array}$} & Air Flow Rate & \multicolumn{2}{|c|}{$\begin{array}{c}\text { Core } \\
\text { Temperature }\end{array}$} & \multirow{2}{*}{$\begin{array}{c}\text { Time to Reach } \\
\text { Core Temp } \\
\text { Limit } \\
\text { Hours }\end{array}$} \\
\hline $\operatorname{Deg} C$ & Deg F & $\mathrm{m} / \mathrm{s} \quad(\mathrm{acfm})$ & Deg C & Deg F & \\
\hline 22.2 & 72 & $0.0049 \quad(20)$ & 38.00 & 100.4 & \\
\hline 22.2 & 72 & $0.0085 \quad$ (35) & 37.56 & 99.6 & \\
\hline 22.2 & 72 & $0.0122 \quad(50)$ & 37.39 & 99.3 & \\
\hline 22.2 & 72 & $0.0244 \quad(100)$ & 37.22 & 99.0 & \\
\hline 23.3 & 74 & $0.0049 \quad(20)$ & $>38.89$ & $>102.0$ & 16.59 \\
\hline 23.3 & 74 & 0.0085 & $>38.89$ & $>102.0$ & 35.90 \\
\hline 23.3 & 74 & 0.0122 & 39.17 & 100.7 & \\
\hline 23.3 & 74 & $0.0244 \quad(100)$ & 37.44 & 99.4 & \\
\hline 24.4 & 76 & $\begin{array}{ll}0.0049 & (20)\end{array}$ & $>38.89$ & $>102.0$ & 8.64 \\
\hline 24.4 & 76 & $0.0085 \quad(35)$ & $>38.89$ & $>102.0$ & 11.09 \\
\hline 24.4 & 76 & $0.0122 \quad(50)$ & $>38.89$ & $>102.0$ & 14.67 \\
\hline 24.4 & 76 & $0.0244 \quad(100)$ & 38.28 & 100.9 & \\
\hline 25.5 & 78 & $0.0049 \quad(20)$ & $>38.89$ & $>102.0$ & 5.88 \\
\hline 25.5 & 78 & $0.0085 \quad(35)$ & $>38.89$ & $>102.0$ & 6.81 \\
\hline 25.5 & 78 & 0.0122 & $>38.89$ & $>102.0$ & 7.83 \\
\hline 25.5 & 78 & $0.0244 \quad(100)$ & $>38.89$ & $>102.0$ & 13.03 \\
\hline 31.1 & 88 & 0.0049 & $>38.89$ & $>102.0$ & 2.16 \\
\hline 31.1 & 88 & 0.0085 & $>38.89$ & $>102.0$ & 2.24 \\
\hline 31.1 & 88 & 0.0122 & $>38.89$ & $>102.0$ & 2.30 \\
\hline 31.1 & 88 & 0.0244 & $>38.89$ & $>102.0$ & 2.48 \\
\hline 35.6 & 96 & 0.0049 & $>38.89$ & $>102.0$ & 1.40 \\
\hline 35.6 & 96 & 0.0085 & $>38.89$ & $>102.0$ & 1.41 \\
\hline 35.6 & 96 & 0.0122 & $>38.89$ & $>102.0$ & 1.42 \\
\hline 35.6 & 96 & $0.0244 \quad(100)$ & $>38.89$ & $>102.0$ & 1.44 \\
\hline
\end{tabular}

cabin air temperatures were $32.2^{\circ} \mathrm{C}\left(90^{\circ} \mathrm{F}\right)$ and $22.2^{\circ} \mathrm{C}\left(72^{\circ} \mathrm{F}\right)$, for the unsuited and suited configurations, respectively. Clearly, the capability to remove the suits would be highly favorable for controlling core body temperature in a prolonged postlanding scenario. Air flow rate is also an important factor.
A preliminary analysis of the cabin temperature and humidity increase using ARPCS2AT2 [11], a computer math model for determining atmospheric pressure and composition control, indicated for the low flow rate cases $0.0049 \mathrm{~m} / \mathrm{s}$ (20 acfm) that air temperatures would rise by about $4.4^{\circ} \mathrm{C}\left(8^{\circ} \mathrm{F}\right)$ for a crew of 6 and assuming a cabin volume of $15.6 \mathrm{~m}^{3}\left(550 \mathrm{ft}^{3}\right)$. Humidity also increased significantly. This study modeled the wall temperature as a constant, and did account for "soakback" heating from re-entry.

\section{Operational Implications and Concerns}

The above results constituted a significant concern for post-landing crew survival under offnominal conditions in warm, tropical ocean areas. Despite the relaxation of the original environmental specifications for water landings, it was found that approximately 24 percent of randomly-located water landings would still result in interior cabin temperatures too warm for 36 hours of crew survival inside the capsule with the hatches closed, even if the crew removed their pressure suits after landing. This led to a recommendation to delete the words "with the hatch closed" from the high-level water survival requirement cited above. In the event that postlanding cabin temperatures were too warm for comfort, the crew would need to open the hatch and transfer to an inflatable life raft, which was already included on the Orion crew equipment list. This operational solution was deemed acceptable by some, since, for randomly-located water landings, the probability of high temperatures requiring crew egress to the life raft occurring simultaneously with rough sea conditions prohibiting crew egress was calculated at approximately $0.0002(0.02 \%)$.

However, others remained concerned about the ability of the crewmembers, who might be physically deconditioned after a long stay in space, to even remove their pressure suits after landing, much less egress the vehicle and get into a life raft. A second, more detailed study was therefore initiated, with the objective of determining what would be required in order to provide sufficient cooling after landing so that the crew would not need to remove their pressure suits or egress the vehicle until rescue and recovery forces arrived. Among the additional factors to be considered in the second study, which were not addressed in the first, were: 
- Additional heating within the vehicle caused by re-entry

- Additional heating caused by solar energy on the outside of the vehicle as it floated in the water after landing

- Integrated transient modeling of the cabin wall temperature, air temperature and cabin humidity

- Cooling effect of the water on the outside of the vehicle

- Hourly variations in the air and water temperatures at the landing site

- A more conservative upper limit on the core body temperature of the astronauts of approximately $100.5^{\circ} \mathrm{F}$, instead of the 102.0 ${ }^{\circ} \mathrm{F}$ used in the first study

- Transient metabolic heat effects due to physical exertion from removing the suit (a demanding task, especially for deconditioned crewmembers)

This ongoing analysis effort is being led by Cindy Cross of Johnson Space Center, Crew and Thermal Systems Division, and involves a team of analysts, including the authors, and will be the subject of a future paper.

\section{Conclusions}

If some active means of rejecting the crew's body heat is not provided, the most important factor in minimizing the risk of crew overheating becomes removing the suit. Increasing the rates of air flow and air exchange with the outside environment are also important factors in controlling cabin humidity, cabin air temperature, and the crew's body temperatures.

Based on a desire to permit the crew to remain in their suits for a reasonable period of time after landing, even in a warm environment, options are currently being investigated which will provide some active cooling to the crew after landing. Since all the options identified to date involve at least some weight increase to the vehicle, this is proving to be a very challenging integrated problem, requiring multiple iterations of analysis, system design, and review.

\section{Acknowledgement}

The authors gratefully acknowledge the preliminary cabin atmosphere modeled by Sharon Lafuse of Johnson Space Center, Crew and Thermal Systems Division.

\section{REFERENCES}

1. Swenson, Loyd S. Jr., Grimwood, James M., and Alexander, Charles C. This New Ocean: A History of Project Mercury. Washington, U.S. Government Printing Office, NASA Special Publication 4201, 1989.

2. Hacker, Barton C., and Grimwood, James M. On the Shoulders of Titans: A History of Project Gemini. Washington, U.S. Government Printing Office, NASA Special Publication 4203, 1977.

3. Wissler, E. H., "Mathematical simulation of human thermal behavior using whole body models." In: Schitzer, A., Eberhart, R.C., eds. Heat Transfer in Biology and Medicine, Vol. 1. New York: Plenum Press; 1985. Chapter 13.

4. Kesterson, M., "User's Guide and Documentation for Wissler Visual Basic Human Thermal Model Version JSC1.0", Jacobs Sverdrup, Engineering ans Science Contract Group, ESCG-447006-TEAN-DOC-0051, May 2, 2006

5. Drew, A. C., Kaufman, J. W., and G. K. Askew, "Effectiveness of NASA 1032 \& 1035 and Air Force 1030 \& 1034 Suits in Protection Against Cold Water Hypothermia," Naval Air Warfare Center - Aircraft Division, Report No. NAWCADWAR-92056-60, August 16, 1992.

6. Waguespack, G, and Pantermuehl J. D., "An Investigation of Advanced Crew Escape Suit (ACES) Thermal Performance for Normal and Deconditioned Astronauts", Jacobs Engineering, Engineering and Science Contract Group, ESCG-4470-07-TEANDOC-0005, January 11, 2008. 
7. Nyberg, K. L., Diller, K. R. and E. H. Wissler, "Model of Human/Liquid Cooling Garment Interaction for Space suit Automatic Thermal Control", Transactions of the ASME, Vol. 123, pp. 114-120.

8. Florey, R. J., "Launch Entry Suit Model Wissler / Metman Comparison", MSAD04-0356, Lockheed Martin Document, September 30, 2004.

9. Kuznetz, L. H., Gernhardt, M. and G. C. Bue, "Airlock Retreat Metabolic Data Analysis", NASA/TP-2007-213737, October 2007.

10. Jones, J. A., NASA Flight Surgeon, Lead for Exploration Medical Operations, personal communication, January 2007.

11. Lafuse, S., Jeng, F., Stafford, K., and Lucas, G., "ARPCS2AT2:A Tool for Atmospheric Pressure and Composition Control Analysis", $33^{\text {rd }}$ International Conference on Environmental Systems, Vancouver BC, Canada , 2003. 
